\title{
Chronic effects of exhausting exercise and overtraining on the immune response: $T_{h} 1$ and $T_{h} 2$ profile
}

\author{
Thiago Teixeira Guimarães $1,2,3^{*}$, Rodrigo Terra ${ }^{1}$, Patrícia Maria Lourenço Dutra1,2
}

REVIEW ARTICLE

\begin{abstract}
Although physical inactivity figures as one of the main causes attributed to mortality, the damage caused by excessive exercise is also a reality. Professional athletes, amateur or uncompetitive modalities beneficiaries are often affected by deleterious conditions resulting from excessive exercise, such as neurological, endocrine and immune origin. The thin line between losses and benefits of successive fatiguing sessions effort depends on the understanding of concepts and methodological training principles. Exercise may have a paradoxical relationship and its consistent prescription in terms of public health depends on a better understanding of their cellular mechanisms. In this sense, the purpose of this review was to explore a promising topic in sports science, able to contribute to elucidate such mechanisms: $T_{h} 1$ and $T_{h} 2$ profile of the immune response related with chronic exhausting exercise and overtraining.

Keywords: overtraining, exhaustion, immune system, physical activity, cytokines.
\end{abstract}

\section{INTRODUCTION}

Although the expectation of global life has increased, the number of people affected by chronic diseases, such as cardiovascular, diabetes, several types of cancer, mental disorders, bone and joint diseases has also increased (Handschin \& Spiegelman, 2008; Lee et al., 2012). Physical inactivity figures as one of the main causes attributed to mortality (Hallal et al., 2012). According to the World Health Organization (2012), in addition to causing suffering, functional dependence, intangible costs on health systems and reduced quality of life, these diseases account for $58.5 \%$ of all deaths worldwide.

On the other hand, the damage caused by excessive exercise is also a reality. The intense physical exercise can optimize performance and health (Gohil \& Brooks, 2012), however, strenuous loads of mental and physical stress can cause numerous deleterious conditions such as overtraining syndrome, pathological remodeling and heart arrhythmia, and muscular and skeletal injuries. The immune imbalance seems to be the origin of the problem (Smith, 2000). In this sense, the purpose of this review is to explore a promising topic in sports science, able to contribute to the elucidation of such mechanisms: $T_{h} 1$ and $T_{h} 2$ profile of the immune response related with chronic exhausting exercise and overtraining. Few chronic studies involving protocols of exhaustion and overtraining were carried out to investigate the change in the relationship between $T_{h} 1$ and $T_{h} 2$ cells. For such, the following topics will be addressed: 1) Thin line between risks and benefits of heavy physical exercise; 2) General characteristics of the immune response; 3) Basic considerations on the immune response to exercise; 4) Chronic effects of exhaustive exercise and overtraining: $T_{h} 1$ and $T_{h} 2$ profile; 5 ) Physical inactivity, excessive exercise and public health.

\footnotetext{
Manuscript received at September 26 ${ }^{\text {th }} 2016$; Accepted at April $11^{\text {th }} 2017$

${ }^{1}$ Laboratory of Protozoan Biochemistry and Immunophysiology of Exercise, LIFE, Department of Microbiology, Immunology and Parasitology, Faculty of Medical Sciences, University of the State of Rio de Janeiro, UERJ, Brazil

${ }^{2}$ Post-Graduation Program in Exercise and Sport Sciences - UERJ - Brazil

${ }^{3}$ Laboratory of Exercise Physiology, LAFIEX, Estácio de Sá University, UNESA, Rio de Janeiro, Brazil

* Autor correspondente: Rua Sargento João Lopes, 608, Ilha do Governador, Rio de Janeiro, Brasil, CEP: 21931-420.

Faculdades. E-mail: thiagotguimaraes@yahoo.com.br
} 
Thin line between risks and benefits of heavy physical exercise

Exercise has been considered a "polypill" (Fiuza-Luces, Garatachea, Berger, \& Lucia, 2013), able to promote numerous biological and functional benefits. There are intense exercise protocols potentially beneficial, such as high intensity interval training, for example (Burgomaster et al., 2008; Burgomaster, Hughes, Heigenhauser, Bradwell, \& Gibala, 2005; Gibala \& McGee, 2008). It can be found in the literature results pointing out that maximum exercise active areas of the brain limbic system, regions could be related to the promotion of pleasure, emotions and rewards (Guimarães et al., 2014; Guimarães \& Deslandes, 2014). Other positive examples of high intensity exercise include the greater impact on energy expenditure (and possibly on body composition), in addition to the overreaching, temporary exhaustion induced by excessive training, followed by physiological overcompensation and improvement of physical fitness.

Meeusen et al. (2006) defined functional overreaching as a short-term performance decrement without severe psychological or other lasting negative symptoms that eventually leads to improvement in performance after days of recovery (Meeusen et al., 2006). This condition is relatively easy to be recovered in the short term, between two and four weeks (Fry \& Kraemer, 1997; Fry, Morton, \& Keast, 1991). Meeusen et al. (2006) characterized nonfunctional overreaching as a performance decrement that can be reversed after weeks or months of recovery, while a performance decrement in overtraining syndrome can last months to years. It has been proposed that overreaching is a stage prior to overtraining (Rogero, Mendes, \& Tirapegui, 2005). Short periods of rest between exercise sessions, in addition to increases in volume and intensity of training, can make the practitioner routine increasingly exhausting (Rogero et al., 2005). Individual differences in recovery time, ability to perform and tolerate physical effort, the impact of adverse weather conditions, lack of nutritional planning (control of carbohydrates, amino acids and hydration, for example) and other stressors not related to training (sleep, diet, family, studies, work, leisure, finances) may explain why each practitioner has a different answer for the same routine or training planning (Freitas, Miranda, \& Bara Filho, 2009; Wanner, Wilke, \& Duffield, 2016).

Amateur or professional athletes are often affected by deleterious conditions resulting from excessive exercise, such as neurological, endocrine and immune. These changes are the overtraining syndrome characteristics, involving mood and anxiety disorders, depression, general apathy, emotional instability, loss of appetite, sleep disorders, hormonal changes, increased heart rate at rest and increased vulnerability to infection and injury in addition to muscle and joint pain (Kellmann, 2010; Matta Mello Portugal et al., 2013; Reardon \& Factor, 2010; Schaal et al., 2011). Overtraining can be defined as a condition of poor adaptation to a chronic period of excessive stress caused by physical exertion, resulting in the development of the syndrome, compromising the health and sports performance (Kreher \& Schwartz, 2012).

The prevalence of the overtraining is rarely studied, but it is estimated that $60 \%$ of marathoners, $50 \%$ of football players and $33 \%$ of basketball players have experienced its symptoms (Armstrong \& VanHeest, 2002). However, frequently, fitness programs for people who do not aim the competition involving endurance exercise, strength and speed also cause undesirable acute or chronic damage and side effects (Rogero et al., 2005). One of the most common symptom or consequence of the muscle damage suffered by beginners is the delayed onset muscle soreness, characterized as a feeling of discomfort in the skeletal muscle, which occurs a few hours after exercise, triggered by inflammation from excessive overloads (Foschini, Prestes, \& Charro, 2007; Tricoli, 2001). In addition to beginners, severe stress caused by physical exertion in noncompetitive environment can also lead to extreme complications, as in the study of case presented in 2011, during the annual meeting of the American College of Sports Medicine (Hadeed, Kuehl, Elliot, \& Sleigh, 2011). Three 
days after a session of intense exercise, based on the Crossfit method, a 33 year old male, previously asymptomatic and physically active, experienced a condition of rhabdomyolysis (Hadeed, Kuehl, Elliot, \& Sleigh, 2011). This syndrome is characterized by damage to the skeletal muscles, the result of extravasation of intracellular content (Criddle, 2003; Lopes \& Costa, 2013). Microtraumas from exercise may include disruption of extracellular matrix, basement membrane, and the sarcolemma, resulting in the release of intracellular proteins such as myoglobin, lactate dehydrogenase, aspartate aminotransferase and creatine kinase (CK), for example, into the bloodstream (Catanho da Silva \& Macedo, 2011; Lazarim et al., 2009). When the stress caused by physical effort is controlled, the degenerative microtrauma are followed by a regenerative tissue repair phase resulting in remodeling of damaged tissue (Catanho da Silva \& Macedo, 2011; Smith, 2004). However, excessive stress can result in muscle weakness, myalgia, nausea, renal failure or even lead to death (Lopes \& Costa, 2013).

Table 1

Summary of risks and benefits of exercise in prolonged durations, extreme loads and/or high frequency.

\begin{tabular}{l} 
Potential Benefits \\
\hline Overreaching; \\
\hline $\begin{array}{l}\text { Ancreased caloric expenditure, reduced body fat; } \\
\text { pleasure. }\end{array}$ \\
$\begin{array}{l}\text { General the limbic system of brain rewards, } \\
\text { response }\end{array}$
\end{tabular}

The immunological response may be understood in two steps: innate and adaptive response. The innate response includes physical barriers (i.e., skin), chemical (i.e., tear complement system) and the participation of cells such as macrophages, neutrophils, dendritic cells, natural killer cells (NK) and microbicides molecules such as nitric oxide (NO) and superoxide anion (O2-). The adaptive immune response involves mainly $\mathrm{T}$ (TCD4 ${ }^{+}$ and $\mathrm{TCD}^{+}$) and $\mathrm{B}$ lymphocytes and their products, cytokines and antibodies, respectively. It can be divided into humoral (mediated for
Excessive endurance exercise in people with different levels of physical fitness, as well as muscular and skeletal injuries, can induce pathological remodeling of the heart structures and adjacent arteries (O'Keefe et al., 2012). Marathons, ultramarathons, triathlons, too long bike races, can cause acute volume overload in the atria and ventricles, with transient decreases in ventricular ejection fraction and cardiac biomarker elevations, which return to normal within a week. Over months and years of repetitive stress, this process may result in fibrosis of the myocardium, particularly in atria, ventricles and interventricular septum, which may develop fibrillations and arrhythmias (O'Keefe et al., 2012; Patil et al., 2012).

The desirable effects of exercise seem to depend on an adequate dose, or a dose that cannot cause side effects. Excessive exercise can damage health of practitioners from many different levels of physical fitness and sports purposes, inducing a reduction in physical performance and ends the competitive athlete's career early. Table 1 summarizes possible risks and benefits of exercise in prolonged durations, extreme loads and/or high frequency.
Overtraining syndrome, cellular and functional lesions; Pathological remodeling of the heart and arrhythmias; Loss of performance and health;

Reduction of adherence to exercise, physical inactivity and development of chronic diseases.

antibodies) and cellular immune response (cellmediated, such as $\mathrm{T}$ lymphocytes and macrophages). The $\mathrm{TCD}^{+}$lymphocytes (helper/helper-Th0) can differentiate into various cell subpopulations as $\mathrm{T}_{h} 1$ (T helper type 1) and $T_{h} 2$ ( $T$ helper type 2 ), that produce different standards of cytokines (Del Prete, 2008; Romagnani, 1991; Terra, Silva, Salerno, \& Dutra, 2012). The differentiation of $\mathrm{TCD}^{+}$in $\mathrm{T}_{\mathrm{h}} 1$ lymphocytes can be stimulated by interleukin 12 (IL-12) produced by antigenpresenting cells (macrophages and dendritic cells), whereas differentiation into $\mathrm{T}_{\mathrm{h}} 2$ is induced by autocrine action of IL-4 produced by 
$\mathrm{TCD}^{+}$. The $\mathrm{T}_{\mathrm{h}} 1$ cells predominantly produce interferon-gamma (IFN- $\gamma$ ) and are related to cellular immune response control caused by intracellular microorganism's infections. The $\mathrm{T}_{\mathrm{h}} 2$ cells produce mainly IL- 4 and are related to the humoral immune response and control of extracellular infections. Various factors such as predominant cytokines in the activation microenvironment, costimulatory molecules, the type of antigen and early events occurring during the innate immune response involving dendritic cells and NK cells can drive predominant response, determining control or not of an infection (Ostrowski, Rohde, Asp, Schjerling, \& Pedersen, 1999; Pedersen \& Febbraio, 2008; Pedersen \& Hoffman-Goetz, 2000; Terra et al., 2012).

\section{Basic considerations on the immune response to exercise}

According to the American College of Sports Medicine, aerobic activities ranging from 40 to $59 \%$ of $\mathrm{VO}_{2 \max }, 55$ and $69 \%$ of maximum heart rate and 12-13 on the Borg scale are considered moderate, while aerobic activities ranging from 60 to $84 \%$ of $\mathrm{VO}_{2 \max }, 70$ and $89 \%$ of maximum heart rate and 14-16 on the Borg scale are considered high intensity (ACSM, 1998; Febbraio \& Pedersen, 2002; Pedersen \& Febbraio, 2008). The International Society of Exercise and Immunology (ISEI), in its official position, points out that immune dysfunction observed after exercise is more pronounced when the effort is continuous, prolonged ( $>1.5$ hours) and held in intensity ranging from moderate to high (55 and $75 \%$ of $\mathrm{VO}_{2 \max }$ ) (Pedersen et al., 2003; Walsh et al., 2011).

During and immediately after the exertion the leukocytes appear to suffer an increase (transient leukocytosis), followed by a fall (leucopenia) (Catanho da Silva \& Macedo, 2011). The period in which agents of the immune system are suppressed after the exhaustion caused by a training session or competitive event is known as the "window of opportunity" (Febbraio \& Pedersen, 2005). The increased risk of respiratory tract infections or other deleterious condition from the opportunity for pathogens may vary within one to nine hours
(Pedersen \& Fischer, 2007), 72 hours (Steensberg et al., 2000) or even two weeks (Fischer et al., 2004). In addition, it has been hypothesized that overtraining begins at the time when new strenuous exercise sessions are performed without the necessary time to recover from immunosuppression (Nielsen \& Pedersen, 2008).

Mechanical, hormonal and metabolic factors can modulate the immune response to exercise (Costa Rosa \& Vaisber, 2002). As examples of mechanical factors, hypoxia, hyperthermia and muscle injury are capable of generating a localized inflammatory process (Costa Rosa \& Vaisber, 2002). Overtraining induced by downhill running training sessions is associated with DNA damage in peripheral blood and skeletal muscle cells, with oxidative stress in skeletal muscle cells and total blood (Pereira et al., 2013). DNA damage observed in lymphocytes, provoked by strenuous exercise, may compromise immune function (Dong et al., 2011; Wierzba, Olek, Fedeli, \& Falcioni, 2006).

The hypothalamus is the structure responsible for coordinating responses resulting from the interaction between the nervous system and secretory glands of hormones (cortisol and growth hormone, for example). Its action changes when there is a neuroendocrine imbalance (Mackinnon, 2000; Meeusen et al., 2004; Smith, 2004). Cytokines are able to modulate the activity of the hypothalamicpituitary-adrenal axis and other areas of the brain responsible for mood control and anxiety. Activation of the autonomic nervous system and the hypothalamic-pituitary-adrenal axis together with suppression of the hypothalamic-pituitarygonadal axis can be governed by cytokines such as IL-1 $\beta$, IL-6 and TNF- $\alpha$ representing consequences related to the overtraining syndrome (Smith, 2000). Athletes with chronic pain have enhanced production of IL-1, IL-2, TNF- $\alpha$ and IFN- $\gamma$ and reduced performance in the ergospirometric test (Vaisberg, de Mello, Seelaender, dos Santos, \& Costa Rosa, 2007).

In relation to metabolism, during catabolic states like infections, surgeries, traumas, acidosis and strenuous physical exercises, plasma glutamine undergoes a reduction 
(Mackinnon, 2000), correlating with an increase in symptoms of upper respiratory tract infections (dos Santos, Caperuto, de Mello, \& Costa Rosa, 2009). Several studies have shown a decrease in plasma glutamine concentration after exhaustive exercise in humans and animals (Bassit, Sawada, Bacurau, Navarro, \& Costa Rosa, 2000; Castell, 2002; dos Santos et al., 2009; Koyama, Kaya, Tsujita, \& Hori, 1998; Walsh, Blannin, Robson, \& Gleeson, 1998), as well as in the presence of overtraining syndrome (dos Santos et al., 2009; Parry-Billings et al., 1992; Rowbottom, Keast, Goodman, \& Morton, 1995). Macrophages use high rates of glutamine to generate energy and biosynthesis (dos Santos et al., 2009). Mice submitted to moderate and strenuous eight weeks training protocols, relative to sedentary control, suffered an increase in macrophage post-exercise function, which was supported by enhanced glutamine consumption and metabolism (dos Santos et al., 2009).

Insulin metabolism also appears to be compromised by overtraining status, affecting factors related to immune function (Pereira et al., 2014). Besides the liver suffer an up regulation of gluconeogenesis, promoting a high-caloric state and redirecting even more amino acids (like glutamine) to this function, insulin presents its metabolism altered. An eight-week protocol involving three groups of rats under different training combinations (sedentary, moderate, and strenuous), evidenced an impaired insulin signaling pathway with concomitant increases in enzymatic complex linked to the cellular response to inflammation, the stress-activated protein kinases/Jun aminoterminal kinases and the suppressor of cytokine signaling 3 (SOCS3) (Pereira et al., 2014).

\section{Chronic effects of exhaustive exercise and overtraining: $T_{h} 1$ and $T_{h} 2$ profile}

Even if several studies associate extreme exercise damages with immunosuppression, the increase in incidence of disease is not exclusive of immunosuppression, but, above all, a change in the immunological profile, from an increase in humoral immunity coupled with the suppression of cellular immunity (Lakier Smith, 2003). While the moderate intensity exercise promotes a protection against infections caused by intracellular microorganisms, because it directs the immune response to the predominance of a response profile of $T_{h} 1$ type, vigorous activities generate increasing concentrations of antiinflammatory cytokines. This condition promoting the predominance of a $\mathrm{T}_{\mathrm{h}} 2$ response profile, in order to decrease the muscle tissue damage resulting from inflammation, although this may result in increased susceptibility to infections (Terra et al., 2012).

Data collected by Terra et al. (2013) showed that lymph nodes cells from mice submitted to swimming activity of moderate intensity for 12 weeks presented an elevation in IFN- $\gamma$ and TNF$\alpha$ concentrations and IL- 4 and IL- 10 significantly decreased compared to sedentary group. These data suggest that moderate exercise promote the predominance of a protective immune response type $T_{h} 1$ in mice (Terra et al., 2013). On the other hand, a review written by Smith (2000) suggests that trauma generated in muscle and skeletal system, from the extreme stress provoked by exercise, produce large amounts of proinflammatory cytokines such as IL- $1 \beta$, IL-6 and TNF- $\alpha$ (Smith, 2000). The positive feedback of the anti-inflammatory components becomes imminent and the imbalance in $\mathrm{T}_{\mathrm{h}} 1$ and $\mathrm{T}_{\mathrm{h}} 2$ profile can reflect a disturbing condition of homeostasis. Successive chronic stimuli, without proper recovery of stable physiological state, may develop symptoms related to overtraining.

Few studies, however, have tested the hypothesis that $\mathrm{T}_{\mathrm{h}} 1$ and $\mathrm{T}_{\mathrm{h}} 2$ profile are chronically altered by overtraining. There are ethical limitations in studies with humans and animals, therefore, are more frequently used. Despite the different protocols of chronic exhaustion and populations used, the results indicate a predominance of the $T_{h} 2$ response on $\mathrm{T}_{\mathrm{h}} 1$.

\section{Protocols of four to six days of exhaustion.}

Mice experienced a suppression in antigen presentation by macrophages three and 24 hours after four days of exhaustive training when 
compared to moderate group (Ceddia \& Woods, 1999). Macrophages are antigen presenting cells capable of causing differentiation of $\mathrm{TCD}^{+}$ lymphocytes into $T_{h} 1$. The authors suggested that cellular immunosuppression is a consequence in reducing differentiation of $T_{h} 1$ new cells, causing an imbalance in $\mathrm{T}_{\mathrm{h}} 1$ and $\mathrm{T}_{\mathrm{h}} 2$ profile. In another study, seven cyclists under six days of intensified training also experienced an imbalance in the ratio $T_{h} 1 / T_{h} 2$ immediately after an exhaustive effort session and the end of two weeks of rest (Lancaster et al., 2004). It was observed a reduction in IFN- $\gamma$ while IL-4 remained unchanged. Therefore, the ratio IFN$\gamma / \mathrm{IL}-4$ reduced with severe stress and was associated with the window of opportunity (Lancaster et al., 2004).

Studies with longer intervention time (overtraining).

The study of Ru and Peije (2009) found that eight rats submitted to nine weeks of progressive training, six days a week, provoked a cellular immunosuppression by predominance of $\mathrm{T}_{\mathrm{h}} 2$ response, reduced systemic hemoglobin concentration and decreased in testosterone and corticosterone 36 hours after the last training session. Seven days after the last session, the authors found in the spleen a reduction of natural killer T cells and IFN- $\gamma$ in addition to IL4 increased, unbalancing the ratio $\mathrm{T}_{\mathrm{h}} 1 / \mathrm{T}_{\mathrm{h}} 2$ through IFN- $\gamma /$ IL-4 compared to the control group (Ru \& Peijie, 2009).

Farhangimaleki et al. (2009) found in cyclists that combined a maintenance of intensity with a decrease in the duration (tapering) within one to three weeks, immediately after eight weeks of training with increasing volume, an improvement in performance compared to a control group. The control group, who trained for eleven weeks progressively from the first to the eleventh, did not improve performance as well as IL- $1 \beta$, IL- 6 and TNF- $\alpha$ increased in relation to tapering group. Although the authors did not evaluate the $T_{h} 2$ profile, the findings suggested the importance of tapering period to prevent disturbances in physiological homeostasis, risk of infections and fatigue (Farhangimaleki, Zehsaz, \& Tiidus, 2009).

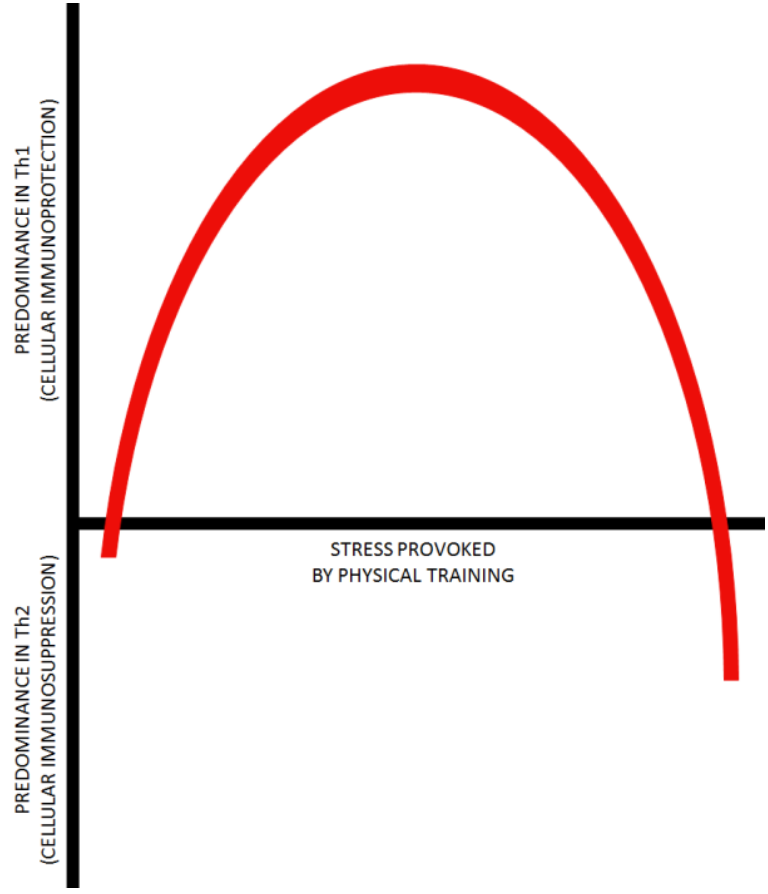

Figure 1. Excessive chronic stress caused by physical training generates an imbalance in $T_{h} 1$ and $\mathrm{T}_{\mathrm{h}} 2$ profile with predominance in $\mathrm{T}_{\mathrm{h}} 2$, cellular immunosuppression, increased susceptibility to infections, signs and symptoms of overtraining. The sedentary condition, studied through control groups without exercise, also represents risks to cellular immunity and health. Moderate training seems to promote the balance between $\mathrm{T}_{\mathrm{h}} 1$ and $\mathrm{T}_{\mathrm{h}} 2$ with predominance in $T_{h} 1$, generating a cellular immunoprotected response.

Gholamnezhad et al. (2014) investigated the effect of eight weeks of moderate training and eleven weeks of severe training (overtraining), immediately, 24 hours and two weeks after in the plasma concentration of cytokines. Although TNF- $\alpha$ has increased in overtraining and overtraining post two weeks recovery, IL-10 and IL-4 increased in both conditions, and IFN- $\gamma$ increased just at moderate group. Even though the authors have not shared the results of physical capacity, moderate training promoted cellular immunity while in other groups, including the control, was observed cellular immunosuppression

(Gholamnezhad, Boskabady, Hosseini, Sankian, \& Khajavi Rad, 2014). These groups had a response directed to the $T_{h} 2$ profile while the response of moderated group was directed to the $T_{h} 1$ profile. In this study, two weeks of recovery (tapering) were not enough to reverse the cellular immunosuppression, as the findings of 
Farhangimaleki et al. (2009). Figure 1 summarizes the changes of different types of chronic stress caused by physical training in $T_{h} 1$ and $\mathrm{T}_{\mathrm{h}} 2$ profile.

Overtraining can be seen as the third stage of the General Adaptation Syndrome, originally described by Hans Selye in 1936. The depletion stage (third stage) refers to recover for survival, unlike the latter, in which the body resists the alarm (first stage) and adapts. The third stage is to protect the body against excessive physiological stress. The signs and symptoms of overtraining syndrome are the positive precaution point of view against even more severe damage (Smith, 2000). Numerous models to explain the mechanisms of acute and chronic fatigue have been developed, but few discuss the relationship of cytokines between the need to repair and regulate afferent feedbacks that process signals that might lead to sensations and feelings of exhaustion (Vargas \& Marino, 2014). The organism requires absolute repose and negative changes in $T_{h} 1$ and $T_{h} 2$ profile appear to help the immune system to repair even greater injuries.

\section{Physical inactivity, excessive exercise and public health}

According to the concept of Hormesis favorable biological responses generally occur due to the properly controlled exposure to stressful stimuli (Radak, Chung, \& Goto, 2008). In the context of public health, not only physical inactivity should figure as the main concern. The exercise has been considered a miracle drug because there is epidemiological evidence to corroborate this statement. However, experimental studies question the effectiveness of any configuration of a physical training program in relation to the intensity and duration. Regular exercise has benefits before the development of overtraining, however, according to Farhangimaleki et al. (2009), overtraining is a poorly understood process.

The state of physical and mental exhaustion not only impairs performance. Its signs and symptoms are consistent with the development of damage to health similar to chronic noncommunicable diseases. The difference between medicine and poison is the dose. With physical exercise does not seem to be different. In this context, we suggest more attention of researchers and policy makers not only to physical inactivity, but at the excessive exercise. The immune imbalance and cellular immunosuppression represent a promising topic in sports science that can help broaden the understanding and discussion of the paradox of exercise.

\section{CONCLUSION}

Chronic exhaustive training may cause the imbalance in $\mathrm{T}_{\mathrm{h}} 1$ and $\mathrm{T}_{\mathrm{h}} 2$ profile with predominance in $T_{h} 2$, resulting in cellular immunosuppression, increased susceptibility to infections, inflammation, signs and symptoms of overtraining. On the other hand, the moderate training seems to promote the balance between $T_{h} 1$ and $T_{h} 2$ with predominance in $T_{h} 1$, generating a cellular immunoprotection.

\begin{tabular}{l}
\hline Acknowledgments: \\
Nothing to declare \\
\hline \\
\hline Conflict of interest: \\
Nothing to declare \\
\hline
\end{tabular}

Funding:

Nothing to declare

\section{REFERENCES}

ACSM (1998). American College of Sports Medicine Position Stand. Exercise and physical activity for older adults. Medicine $\mathcal{E}$ Science in Sports $\mathcal{E}$ Exercise, 30(6), 992-1008.

Armstrong, L. E., \& VanHeest, J. L. (2002). The unknown mechanism of the overtraining syndrome: clues from depression and psychoneuroimmunology. Sports Medicine, 32(3), 185-209.

Bassit, R. A., Sawada, L. A., Bacurau, R. F., Navarro, F., \& Costa Rosa, L. F. (2000). The effect of BCAA supplementation upon the immune response of triathletes. Medicine $\mathcal{E}$ Science in Sports \& Exercise, 32(7), 1214-1219.

Burgomaster, K. A., Howarth, K. R., Phillips, S. M., Rakobowchuk, M., Macdonald, M. J., McGee, S. L., \& Gibala, M. J. (2008). Similar metabolic adaptations during exercise after low volume sprint interval and traditional endurance training 
in humans. The Journal Physiology, 586(1), 151160. doi:10.1113/jphysiol.2007.142109

Burgomaster, K. A., Hughes, S. C., Heigenhauser, G. J., Bradwell, S. N., \& Gibala, M. J. (2005). Six sessions of sprint interval training increases muscle oxidative potential and cycle endurance capacity in humans. Journal of Applied Physiology, 98(6), 1985-1990. doi: 10.1152/japplphysiol.01095.2004

Castell, L. M. (2002). Can glutamine modify the apparent immunodepression observed after prolonged, exhaustive exercise? Nutrition, 18(5), 371-375.

Catanho da Silva, F., \& Macedo, D. (2011). Exercício físico, processo inflamatório e adaptação: uma visão geral Revista Brasileira de Cineantropometria e Desempenho Humano, 13(4), 320-328. doi: 10.5007/1980-0037.2011v13n4p320

Ceddia, M. A., \& Woods, J. A. (1999). Exercise suppresses macrophage antigen presentation. Journal of Applied Physiology, 87(6), 2253-2258.

Costa Rosa, L. F. P. B., \& Vaisber, M. W. (2002). Influência do Exercício na Reposta Imune. Revista Brasileira de Medicina do Esporte, 8(4), 167172. Criddle, L. M. (2003). Rhabdomyolysis. Pathophysiology, recognition, and management. Critical Care Nurse, 23(6), 1422, 24-26, 28 passim; quiz 31-32.

Del Prete, G. (2008). The complexity of the CD4 Tcell responses: old and new T-cell subsets. Parassitologia, 50(1-2), 9-16.

Dong, J., Chen, P., Wang, R., Yu, D., Zhang, Y., \& Xiao, W. (2011). NADPH oxidase: a target for the modulation of the excessive oxidase damage induced by overtraining in rat neutrophils. International Journal of Biological Sciences, 7(6), 881-891.

dos Santos, R. V., Caperuto, E. C., de Mello, M. T., \& Costa Rosa, L. F. (2009). Effect of exercise on glutamine metabolism in macrophages of trained rats. European Journal of Applied Physiology, 107(3), 309-315. doi:10.1007/s00421-009-11306

Farhangimaleki, N., Zehsaz, F., \& Tiidus, P. M. (2009). The effect of tapering period on plasma pro-inflammatory cytokine levels and performance in elite male cyclists. Journal of Sports Science and Medicine, 8(4), 600-606.

Febbraio, M. A., \& Pedersen, B. K. (2002). Musclederived interleukin-6: mechanisms for activation and possible biological roles. The FASEB Journal, 16(11), 1335-1347. doi:10.1096/fj.01-0876rev

Febbraio, M. A., \& Pedersen, B. K. (2005). Contraction-induced myokine production and release: is skeletal muscle an endocrine organ? Exercercise and Sport Science Reviews, 33(3), 114119.

Fischer, C. P., Hiscock, N. J., Penkowa, M., Basu, S., Vessby, B., Kallner, A., . . . Pedersen, B. K. (2004). Supplementation with vitamins C and E inhibits the release of interleukin- 6 from contracting human skeletal muscle. Journal of
Physiology,

$558(2)$,

633-645.

doi:10.1113/jphysiol.2004.066779

Fiuza-Luces, C., Garatachea, N., Berger, N. A., \& Lucia, A. (2013). Exercise is the real polypill. Physiology, 28(5), 330-358. doi:10.1152/physiol.00019.2013

Foschini, D., Prestes, J., \& Charro, M. A. (2007). Relationship between physical exercise, muscle damage and delayed-onset muscle soreness. Revista Brasileira de Cineantropomemtria $e$ Desempenho Humano, 9(1), 101-106. doi: $10.5007 / \% 25 \mathrm{x}$

Freitas, D., Miranda, R., \& Bara Filho, M. (2009). Marcadores psicológico, fisiológico e bioquímico para determinação dos efeitos da carga de treino e do overtraining. Revista Brasileira de Cineantropomemtria e Desempenho Humano, 11(4), 457-465

Fry, A. C., \& Kraemer, W. J. (1997). Resistance exercise overtraining and overreaching. Neuroendocrine responses. Sports Medicine, 23(2), 106-129.

Fry, R. W., Morton, A. R., \& Keast, D. (1991). Overtraining in athletes. An update. Sports Medicine, 12(1), 32-65.

Gholamnezhad, Z., Boskabady, M. H., Hosseini, M., Sankian, M., \& Khajavi Rad, A. (2014). Evaluation of immune response after moderate and overtraining exercise in wistar rat. Iranian Journal of Basic Medical Sciences, 17(1), 1-8.

Gibala, M. J., \& McGee, S. L. (2008). Metabolic adaptations to short-term high-intensity interval training: a little pain for a lot of gain? Exercise and Sport Science Review, 36(2), 58-63. doi: 10.1097/JES.0b013e318168ec1f

Gohil, K., \& Brooks, G. A. (2012). Exercise tames the wild side of the Myc network: a hypothesis. American Journal of Physiology. Endocrinology and Metabolism, 303(1), E18-30. doi:10.1152/ajpendo.00027.2012

Guimaraes, T. T., Costa, B. M. da, Cerqueira, L. S., Serdeiro, A. de C. A., Pompeu, F. A. M. S., Moraes, H. S. de, ... Deslandes, A. C. (2015). Acute Effect of Different Patterns of Exercise on Mood, Anxiety and Cortical Activity. Archives of Neuroscience, 2(1), e18781. https://doi.org/10.5812/archneurosci.18781

Guimarães, T., \& Deslandes, A. (2014). Exercício físico em diferentes intensidades: efeito sobre o humor, ansiedade, cognição e atividade cortical. Novas Edições Acadêmicas.

Hadeed, M. J., Kuehl, K. S., Elliot, D. L., \& Sleigh, A. (2011). Exertional Rhabdomyolysis After Crossfit Exercise Program: 1210. Medicine $\mathcal{E}$ Science in Sports \& Exercise, 43(5), 224-225. https://doi.org/10.1249/01.MSS.0000400606.24 $620 . b c$

Hallal, P. C., Andersen, L. B., Bull, F. C., Guthold, R., Haskell, W., Ekelund, U., \& Group, L. P. A. S. W. (2012). Global physical activity levels: surveillance progress, pitfalls, and prospects. 
Lancet, 380(9838), 247-257. doi:10.1016/S01406736(12)60646-1

Handschin, C., \& Spiegelman, B. M. (2008). The role of exercise and PGClalpha in inflammation and chronic disease. Nature, 454(7203), 463-469. doi:10.1038/nature07206

Kellmann, M. (2010). Preventing overtraining in athletes in high-intensity sports and stress/recovery monitoring. Scandinavian Journal of Medicine $\&$ Science in Sports, 20(Suppl 2), 95102. 0838.2010.01192.x https://doi.org/10.1111/j.1600-

Koyama, K., Kaya, M., Tsujita, J., \& Hori, S. (1998). Effects of decreased plasma glutamine concentrations on peripheral lymphocyte proliferation in rats. European Journal of Applied Physiology and Occupational Physiology, 77(1-2), 25-31.

Kreher, J. B., \& Schwartz, J. B. (2012). Overtraining syndrome: a practical guide. Sports Health, 4(2), 128-138.

https://doi.org/10.1177/1941738111434406

Lakier Smith, L. (2003). Overtraining, excessive exercise, and altered immunity: is this a $\mathrm{T}$ helper-1 versus T helper-2 lymphocyte response? Sports Medicine, 33(5), 347-364.

Lancaster, G. I., Halson, S. L., Khan, Q., Drysdale, P., Wallace, F., Jeukendrup, A. E., . . . Gleeson, M. (2004). Effects of acute exhaustive exercise and chronic exercise training on type 1 and type $2 \mathrm{~T}$ lymphocytes. Exercise Immunology Review, 10, 91106.

Lazarim, F. L., Antunes-Neto, J. M., da Silva, F. O., Nunes, L. A., Bassini-Cameron, A., Cameron, L. C., . . . de Macedo, D. V. (2009). The upper values of plasma creatine kinase of professional soccer players during the Brazilian National Championship. Journal of Science and Medicine in Sport, $12(1), \quad 85-90$. doi:10.1016/j.jsams.2007.10.004

Lee, I. M., Shiroma, E. J., Lobelo, F., Puska, P., Blair, S. N., Katzmarzyk, P. T., \& Group, L. P. A. S. W. (2012). Effect of physical inactivity on major non-communicable diseases worldwide: an analysis of burden of disease and life expectancy. Lancet, 380(9838), 219-229. doi:10.1016/S01406736(12)61031-9

Lopes, C., \& Costa, L. (2013). Rabdomiólise induzida pelo exercício: biomarcadores, mecanismos fisiopatológicos e possibilidades terapêuticas. Revista HUPE, 12(4), 59-65.

Mackinnon, L. T. (2000). Chronic exercise training effects on immune function. Medicine and Science in Sports and Exercise, 32 (7 Suppl), S369-376.

Matta Mello Portugal, E., Cevada, T., Sobral Monteiro-Junior, R., Teixeira Guimarães, T., da Cruz Rubini, E., Lattari, E., . . . Camaz Deslandes, A. (2013). Neuroscience of exercise: from neurobiology mechanisms to mental health. Neuropsychobiology, 68(1), 1-14. doi:10.1159/000350946
Meeusen, R., Duclos, M., Gleeson, M., Rietjens, G., Steinacker, J., \& Urhausen, A. (2006). Prevention, diagnosis and treatment of the Overtraining Syndrome. European Journal of Sport Science, 6(1), 1-14. https://doi.org/10.1080/17461390600617717

Meeusen, R., Piacentini, M. F., Busschaert, B., Buyse, L., De Schutter, G., \& Stray-Gundersen, J. (2004). Hormonal responses in athletes: the use of a two bout exercise protocol to detect subtle differences in (over)training status. European Journal of Applied Physiology, 91(2-3), 140-146. doi:10.1007/s00421-003-0940-1

Nielsen, S., \& Pedersen, B. K. (2008). Skeletal muscle as an immunogenic organ. Current Opinion in Pharmacology, $\quad 8(3), \quad 346-351$. doi:10.1016/j.coph.2008.02.005

O'Keefe, J. H., Patil, H. R., Lavie, C. J., Magalski, A., Vogel, R. A., \& McCullough, P. A. (2012). Potential adverse cardiovascular effects from excessive endurance exercise. Mayo Clinic Proceedings, 87(6), 587-595. doi:10.1016/j.mayocp.2012.04.005

Ostrowski, K., Rohde, T., Asp, S., Schjerling, P., \& Pedersen, B. K. (1999). Pro- and antiinflammatory cytokine balance in strenuous exercise in humans. Journal of Physiology, 515(1), 287-291.

Parry-Billings, M., Budgett, R., Koutedakis, Y., Blomstrand, E., Brooks, S., Williams, C., . . . Newsholme, E. A. (1992). Plasma amino acid concentrations in the overtraining syndrome: possible effects on the immune system. Medicine $\mathcal{E}$ Science in Sports $\&$ Exercise, 24(12), 1353-1358.

Patil, H. R., O'Keefe, J. H., Lavie, C. J., Magalski, A., Vogel, R. A., \& McCullough, P. A. (2012). Cardiovascular damage resulting from chronic excessive endurance exercise. Missouri Medicine, 109(4), 312-321.

Pedersen, B. K., \& Febbraio, M. A. (2008). Muscle as an endocrine organ: focus on muscle-derived interleukin-6. Physiological Reviews, 88(4), 13791406. doi:10.1152/physrev.90100.2007

Pedersen, B. K., \& Fischer, C. P. (2007). Physiological roles of muscle-derived interleukin- 6 in response to exercise. Current Opinion in Clinical Nutrition and Metabolic Care, 10(3), 265-271. doi:10.1097/MCO.0b013e3280ebb5b3

Pedersen, B. K., \& Hoffman-Goetz, L. (2000). Exercise and the immune system: regulation, integration, and adaptation. Physiological Reviews, 80(3), 1055-1081.

Pedersen, B. K., Steensberg, A., Fischer, C., Keller, C., Keller, P., Plomgaard, P., . . . Saltin, B. (2003). Searching for the exercise factor: is IL-6 a candidate? Journal of Muscle Research and Cell Motility, 24(2-3), 113-119.

Pereira, B. C., Pauli, J. R., Antunes, L. M., de Freitas, E. C., de Almeida, M. R., de Paula Venâncio, V., . . . da Silva, A. S. (2013). Overtraining is associated with DNA damage in blood and 
skeletal muscle cells of Swiss mice. BMC Physiology, 13, 11. doi:10.1186/1472-6793-13-11

Pereira, B. C., Pauli, J. R., De Souza, C. T., Ropelle, E. R., Cintra, D. E., Freitas, E. C., \& da Silva, A. S. (2014). Eccentric exercise leads to performance decrease and insulin signaling impairment. Medicine \& Science in Sports \& Exercise, 46 (4), 686694. doi:10.1249/MSS.0000000000000149

Radak, Z., Chung, H. Y., \& Goto, S. (2008). Systemic adaptation to oxidative challenge induced by regular exercise. Free Radical Biology \& Medicine, 44(2), 153-159. doi: 10.1016/j.freeradbiomed.2007.01.029 Reardon, C. L., \& Factor, R. M. (2010). Sport psychiatry: a systematic review of diagnosis and medical treatment of mental illness in athletes. Sports Medicine, $\quad 40(11)$, 961-980. doi:10.2165/11536580-000000000-00000

Rogero, M. M., Mendes, R. R., \& Tirapegui, J. (2005). Neuroendocrine and nutritional aspects of overtraining. Arquivos Brasileiros de Endocrinologia Eamp; Metabologia, 49(3), 359-368. https://doi.org/10.1590/S000427302005000300006

Romagnani, S. (1991). Type $1 \mathrm{~T}$ helper and type $2 \mathrm{~T}$ helper cells: functions, regulation and role in protection and disease. International Journal of Clinical \& Laboratory Research, 21 (2), 152-158.

Rowbottom, D. G., Keast, D., Goodman, C., \& Morton, A. R. (1995). The haematological, biochemical and immunological profile of athletes suffering from the overtraining syndrome. European Journal of Applied Physiology and Occupational Physiology, 70(6), 502-509.

Ru, W., \& Peijie, C. (2009). Modulation of NKT cells and $T_{h} 1 / T_{h} 2$ imbalance after alpha-GalCer treatment in progressive load-trained rats. International Journal of Biological Sciences, 5(4), 338-343.

Saúde., Ministério da Saúde. (2011). Plano de Ações Estratégicas para o Enfrentamento das Doenças Crônicas Não Transmissíveis (DCNT) no Brasil 20112022. Brasília: Ministério da Saúde.

Schaal, K., Tafflet, M., Nassif, H., Thibault, V., Pichard, C., Alcotte, M., . . . Toussaint, J. F. (2011). Psychological balance in high level athletes: gender-based differences and sportspecific patterns. PLoS One, 6(5), e19007. doi:10.1371/journal.pone.0019007

Smith, L. L. (2000). Cytokine hypothesis of overtraining: a physiological adaptation to excessive stress? Medicine $\mathcal{E}$ Science in Sports $\mathcal{E}$ Exercise, 32(2), 317-331.

Smith, L. L. (2004). Tissue trauma: the underlying cause of overtraining syndrome? Journal of
Strength and Conditioning Research, 18(1), 185193.

Steensberg, A., van Hall, G., Osada, T., Sacchetti, M., Saltin, B., \& Klarlund Pedersen, B. (2000). Production of interleukin-6 in contracting human skeletal muscles can account for the exercise-induced increase in plasma interleukin6. Journal of Physiology, 529(1), 237-242.

Terra, R., Alves, P. J., Gonçalves da Silva, S. A., Salerno, V. P., \& Dutra, P. M. (2013). Exercise improves the $T_{h} 1$ response by modulating cytokine and NO production in BALB/c mice. International Journal of Sports Medicine, 34(7), 661666. doi:10.1055/s-0032-1329992

Terra, R., Silva, S. A. G. da, Pinto, V. S., \& Dutra, P. M. L. (2012). Effect of exercise on immune system: response, adaptation and cell signaling. Revista Brasileira de Medicina Do Esporte, 18(3), 208-214. https://doi.org/10.1590/S151786922012000300015

Tricoli, V. (2001). Mecanismos envolvidos na etiologia da dor muscular tardia. Revista Brasileira de Ciência e Movimento, 9(2), 39-44.

Vaisberg, M., de Mello, M. T., Seelaender, M. C., dos Santos, R. V., \& Costa Rosa, L. F. (2007). Reduced maximal oxygen consumption and overproduction of proinflammatory cytokines in athletes. Neuroimmunomodulation, 14(6), 304-309. doi:10.1159/000123155

Vargas, N. T., \& Marino, F. (2014). A neuroinflammatory model for acute fatigue during exercise. Sports Medicine, 44(11), 14791487. doi:10.1007/s40279-014-0232-4

Walsh, N. P., Blannin, A. K., Robson, P. J., \& Gleeson, M. (1998). Glutamine, exercise and immune function. Links and possible mechanisms. Sports Medicine, 26(3), 177-191.

Walsh, N. P., Gleeson, M., Pyne, D. B., Nieman, D. C., Dhabhar, F. S., Shephard, R. J., . . . Kajeniene, A. (2011). Position statement. Part two: Maintaining immune health. Exercise Immunology Review, 17, 64-103.

Wanner, S. P., Wilke, C. F., \& Duffield, R. (2016). Nutritional strategies for maximizing recovery from strenuous exercise in the heat: An important role for carbohydrate (sago) supplementation. Temperature, 3(3), 366-368. https://doi.org/10.1080/23328940.2016.121433 5

Wierzba, T. H., Olek, R. A., Fedeli, D., \& Falcioni, G. (2006). Lymphocyte DNA damage in rats challenged with a single bout of strenuous exercise. Journal of Physiology and Pharmacology: An Official Journal of the Polish Physiological Society, 57 Suppl 10, 115-131. 